Revue internationale de l'économie sociale

Recma

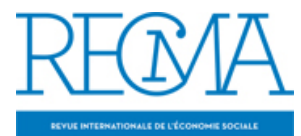

\title{
À la mémoire de Claude Vienney (1928-2001)
}

\section{André Chomel}

Numéro 282, novembre 2001

URI : https://id.erudit.org/iderudit/1023394ar

DOI : https://doi.org/10.7202/1023394ar

Aller au sommaire du numéro

\section{Éditeur(s)}

Institut de l'économie sociale (IES)

\section{ISSN}

1626-1682 (imprimé)

2261-2599 (numérique)

Découvrir la revue

\section{Citer ce document}

Chomel, A. (2001). À la mémoire de Claude Vienney (1928-2001). Revue internationale de l'économie sociale, (282), 5-5.

https://doi.org/10.7202/1023394ar 


\section{À LA MÉMOIRE DE CLAUDE VIENNEY (1928-2001)}

- 'équipe de la Recma et nombre de ses lecteurs sont en deuil de Claude Vienney depuis ce 12 juillet où il nous a quittés. Nos chemins n'ayant cessé de se croiser et parfois de se combiner, depuis rien de moins qu'un demi-siècle, il m'incombe d'évoquer ici, au nom de l'équipe Recma, l'homme que nous avons perdu et l'œuvre qu'il nous a laissée.

Claude Vienney aura été le théoricien et l'analyste français de l'organisation coopérative et d'économie sociale de la seconde moitié du XXe siècle. Passant de la doctrine à la théorie, il a expliqué l'émergence de la forme coopérative et la genèse de sa transformation. Son parcours n'a pas été pour autant limité à la coopération ; il s’est déployé entre recherche, formation des adultes et syndicalisme.

Claude Vienney ne nous parait cependant pas avoir été connu et reconnu dans le monde de l'économie sociale, voire dans celui de l'université, comme l'aurait justifié son œuvre ; le Québec fut toutefois plus clairvoyant à cet égard que sa patrie! Un cahier Recma consacré à Claude Vienney paraîtra prochainement. Il publiera un long interview de lui (par M.-C. Malo et A. Chomel), auquel il s'était " résigné ", ainsi qu'une série de témoignages de ceux qui furent ses compagnons à un titre ou à un autre.

Mais c'est surtout à l'homme que ses amis pensent aujourd'hui. Sa créativité sur le plan conceptuel, son charisme pour l'initiation et la formation laisseront le souvenir d'une personnalité exceptionnelle; hors du commun aussi par la modestie, la discrétion, le profil volontairement effacé quil offrait, jouant de l'humour en tant que de besoin à cet effet. Son protestantisme s'exprimait sans doute là, avec un humanisme et une exigence de lucidité intransigeante.

A son épouse Eliane Vienney, à ses cinq enfants et neuf petits-enfants, l'équipe de la Recma exprime sa respectueuse sympathie. 